\title{
HUBUNGAN ANTARA WORK FAMILY CONFLICT DENGAN PSYCHOLOGICAL WELL-BEING PADA IBU YANG BEKERJA SEBAGAI PERAWAT DI RUMAH SAKIT SUMBER KASIH CIREBON
}

\author{
Ignatia Dimarda Pamintaningtiyas ${ }^{1}$, Christiana Hari Soetjiningsih ${ }^{2}$ \\ Email: ignatiadimardap@gmail.com ${ }^{1}$ \\ Universitas Kristen Satya Wacana
}

\begin{abstract}
Abstrak
Tujuan penelitian ini adalah untuk mengetahui hubungan work family conflict dengan psychological wellbeing pada ibu yang bekerjasebagai perawat di RS Sumber Kasih Cirebon. Hipotesis yang diajukan adalah ada korelasi negatif signifikan antara work family conflict dengan psychological well-being pada ibu yang bekerjasebagai perawat. Subjek dalam penelitian ini adalah ibu yang bekerja sebagai perawat di RS Sumber Kasih Cirebon sebanyak 50 perawat. Pengumpulan data di lakukan dengan skala work family conflict dan skala psychological well-being. Analisis data menggunakan metode korelasi product moment. Hasil penelitian menunjukkan terdapat hubungan negatif signifikan antara work family conflict dengan psychological well-being, dengan nilai $\mathrm{r}=-0,572$ dan nilai signifikansi $=0,000(\mathrm{p}<0,05)$. Artinya semakin tinggi work family conflict maka psychological well-being nya semakin rendah yang dimiliki oleh Ibu yang bekerja sebagai perawat di RS Sumber Kasih Cirebon .Demikian sebaliknya, semakin rendah work family conflictmaka semakin tinggi psychological well-being yang dimiliki ibu yang bekerja sebagai perawat di RS Sumber Kasih Cirebon.
\end{abstract}

Kata Kunci: Work Family Conflict, Psychological Well-Being, Ibu Perawat

PENDAHULUAN

Berdasarkan data dari Badan Pusat Statistik (BPS) pada 30 Juli 2018, Presentase Tenaga Kerja Formal (PRKF) pekerja perempuan meningkat, yang sebelumnya pada tahun 2015 yaitu 37,78 persen dan pada tahun 2017 menjadi 38,63 persen. Terlebih perempuan yang sudah menikah dan mempunyai anak. Menurut Ridzal (dalam munandar dkk, 2018) Perempuan tidak kalah banding dengan laki-laki, dalam segi intelektual, kemampuan, dan keterampilan. Berarti wanita yang sudah menikah memiliki kebebasan untuk menjalankan perannya sebagai istri dan ibu dalam keluarga.

Peningkatan jumlah ibu yang bekerja sering dihubungkan dengan pencapaian tingkat pendidikan yang lebih tinggi. Menurut Ajeng (2016) keputusan seorang ibu untuk bekerja tentunya diikuti oleh manfaat-manfaat bagi dirinya, suami dan anak-anaknya. Nieva dan Gutek (dalam Ajeng, 2016) menulis efek kumulatif dari ibu yang bekerja menurut beberapa ahli yaitu bekerja dapat meningkatkan perasaan kompeten dan well-being. Meningkatnya perasaan kompeten disebabkan oleh gaji yang diterima dan dapat tidak bergantungan secara finansial daan rasa mandiri membantu ibu untuk dapat membantu urusan rumah tangga dan kebutuhan anak dan mempunyai efek rehabilitatatif terhadap kesehatan mental, dapat meningkatkan perasaan well-being (Ajeng, 2016). 
Menurut Ryff (dalam Raprap, 2016) psychological well-being (PWB) merupakan suatu keadaan individu menerima dirinya apa adanya, mampu membentuk hubungan hangat dengan orang lain, memiliki kemandirian dalam tekanan sosial, mampu mengontrol lingkungan eksternal, memiliki arti hidup serta mampu merealisasikan potensi dirinya secara kontinu. PWB bukan hanya kepuasan hidup dan keseimbangan antara efek positif dan negatif, namun PWB melibatkan persepsi keterlibatan dengan tantangan-tantangan selama hidup.

$P W B$ merupakan hal yang harus dimiliki setiap individu. Demikian dengan ibu bekerja untuk mencapai kesejahteraan secara psikologis. Namun kenyatannya kesejahteraan psikologis bukan suatu yang bisa dicapai dengan mudah, terutama ibu bekerja (Indriani dan Inhastuti, 2016). Berdasarkan hasil wawancara yang dilakukan oleh Indriani dan Inhastuti (2016) dengan beberapa subjek ibu yang bekerja memiliki rata rata kesejahteraan yang rendah, dikarenakan Subjek kurang memiliki hubungan dengan keluarga.

Terlebih pada ibu yang berprofesi sebagai perawat. Seorang perawat merupakan ujung tombak pelayanan kesehatan, membangun rasa nyaman kepada pasien dan harus menumbuhkan kognitif positif pada pasien dalam proses penyembuhan. Agar dapat memiliki hubungan yang sehat, seorang perawat harus memahami reaksi emosional manusia dan kesejahteraan psikis.

Berdasarkan hasil wawancara dengan tiga ibu yang bekerja sebagai perawat di RS Sumber Kasih Cirebon penulis melihat fenomena permasalahan pada ibu yang bekerja sebagai perawat di RS Sumber Kasih Cirebon bahwa perawat harus memiliki environmental mastery (penguasaan lingkungan), peka terhadap lingkungan. Seorang perawat harus menyadari seorang pasien marah, depresi, bingung atau takut dan mengambil langkah untuk menangani emosi tersebut dan tidak memperburuk kesehatan pasien. Maka dari itu perawat harus memiliki PWB yang baik, apabila PWB perawat baik maka bisa membantu penyembuhan menurut Sahusilawane, Yulius dan Desi (2017).

Faktor yang mempengaruhi rendahnya PWB pada ibu bekerja adalah work family conflict. Work family conflictyang dialami seorang ibu bekerja terjadi karena adanya ketidakcocokan antara harapan, tuntutan, tekanan dirumah dan di tempat kerja (Indriani dan Inhastuti, 2016). Work family conflict terjadi karena seseorang memiliki lebih peran yang saling bertentangan dan salah satu peran menuntut banyak perhatian. 
Dalam hal ini alasan perawat yang sudah menikah menomerduakan masalah keluarga dan lebih fokus pada pekerjaan mereka.

Hasil wawancara yang dilakukan penulis dengan tiga ibu yang bekerja sebagai perawat di RS Sumber Kasih Cirebon menunjukkan fenomena work family conflict dari ibu yang bekerja sebagai perawat terkadang datang terlambat dikarenakan harus mengurus anak, melakukan tugas ibu rumah tangga seperti memasak, mencuci dan membersihkan rumah, mengurus anak serta mengurus keperluan suami pada pagi hari, lalu bukan hanya itu saja perawat memiliki jam kerja cukup padat beberapa perawat memutuskan untuk menggunakan jasa asisten rumah tangga dalam keperluan keluarga dan juga menitipkan anaknya ketika seorang ibu tersebut harus pergi bekerja. Belum lagi ketika seorang ibu yang bekerja sebagai perawat mendapatkan shift pada malam hari. Yang seharusnya tugas seorang ibu menidurkan anaknya di malam hari atau membimbing anaknya ketika mengerjakan tugas, tapi seorang ibu perawat tersebut tidak bisa melakukannya dikarenakannya dikarenakan harus bekerja.

Shift kerja sistem untuk meningkatkan produksi atau pelayanan selama 24 jam dalam sehari (Rosyad,
2017). Pekerjaan dengan sistem shift memiliki dampak positif dan negatif. Perawat wanita yang bekerja sistem shift lebih rentan mengalami work family conflict yang lebih tinggi karena sistem sift menyita waktu bersama keluarga (Rosyad, 2017). Dikarenakan system Sift menyita waktu keluarga terkhususnya sift malam membuat perawat wanita menjadi lebih memikirkan anak dan keluarga dirumah karena tidak dapat mengurus keluarga sehingga dapat menimbulkanwork family conflict.

Penelitian yang dilakukan Rosyad (2017) di ruang rawat inap RSU Cibabat Cimahi tahun 2016 menunjukkan tingkat work family conflict perawat wanita berada pada kategori tinggi.Perawat adalah profesi yang tidak bisa dikesampingkan dalam rumah sakit, bukan hanya menghadapi dan melayani orang sakit, namun juga berhadapan berbagai masalah peraturan, prosedur, dan birokrasi dari rumah sakit yang memerlukan ketahanan fisik dan mental. Dan pembagian tugas kerja yang kurang dalam pekerjaan mengakibatkan masalah yang terdapat antara keluarga dan pekerjaannya (Amaliya, 2015)..

Work family conflict yang dialami oleh setiap perempuan berbeda. Hal ini juga dikemukakan dalam penelitian yang dilakukan Himan dan Putri (dalam Saman 
dan Eva, 2012) bahwa ibu bekerja (berkarir) mengalami dilema. Seperti yang dikatakan Frone, Russell dan Cooper (dalam Ajeng, 2016) konflik peran ganda merupakan salah satu sumber stres dan mempengaruhi kondisi well-being seseorang. Dikarenakan ibu dituntut untuk memiliki peran ganda yang membuat $P W B$ menjadi rendah ,Sesuai dengan penelitian Sianturi dan Zulkarnain (dalam Indriani dan Inhastuti, 2016) bahwa ada korelasi negatif antara work family conflict dengan $P W B$, yaitu semakin tinggi tingkat work family conflict seseorang maka rendahnya tingkat $P W B$.

\section{TINJAUAN PUSTAKA}

Hubungan antara Work Family Conflict dengan Psychological Well Being

Kesejahteraan merupakan tujuan utama dalam hidup. Kesejahteraan dapat diperoleh melalui beberapa cara, salah satunya dengan bekerja, karna pekerjaan yang layak menjamin individu memperoleh kesejahteraan dalam hidupnya, individu dituntut untuk bekerja keras tujuannya untuk memperoleh kepuasan dalam bekerja. Kepuasan kerja diperoleh dari gaji, beban kerja dan tekanan dalam bekerja. Individu memperoleh kepuasan kerja jika upah sesuai dengan beban kerja dan kepuasan dalam bekerja berdampak pada tujuan hidup.
Tujuan hidup merupakan dimensi dalam psychological well-being (PWB). Menurut Ryff (dalam Ajeng, 2016) menjelaskan bahwa individu dikatakan memiliki psychological well-being tinggi jika memiliki tujuan, niat dan arah dalam tujuan hidup, yang memiliki perasaan bahwa hidup bermakna. Tetapi tidaklah mudah menciptakan psychological wellbeing menurut Ahmad (dalam Sianturi dan Zulkarnain, 2013).

Dalam hal ini individu tidak memenuhi pemenuhan keluarga yang kemudian membuat pemenuhan tuntutan pekerjaan dan tuntutan keluarga menjadi tidak seimbang. Ketidakseimbangan tersebut memunculkan work-family conflict menurut Greenhaus \& Beutell (dalam Sianturi dan Zulkarnain, 2013).

Boyar, Maertz, Mosley dan Carr (dalam Sianturi dan Zulkarnain, 2013) menjelaskan bahwa ambigiuitas kerja berkorelasi positif dengan tuntutan pekerjaan yang dapat menimbulkan workfamily conflict. Hasil studi Lu, Gilmour, Kao \& Huang (dalam Sianturi dan Zulkarnain, 2013) menyatakan bahwa konflik dalam keluarga berkorelasi negatif dengan kebahagiaan individu di tempat kerja, sejalan dengan itu Byron (dalam Sianturi dan Zulkarnain, 2013) menjelaskan bahwa konflik dalam keluarga akan menyebabkan individu 
menjadi kurang berkonsentrasi di tempat kerja, dan menjadi tidak seimbang.

\section{METODE PENELITIAN}

Metode penelitian yang digunakan pada penelitian merupakan metode kuantitatif. Pengumpulan data dalam metode ini menggunakan skala. Alat ukur yang digunakan dalam pengumpulan data adalah skala work family conflict dan skala psychological well being. Subjek dalam penelitian ini sebanyak 50 perawat. Adapun kriteria antara lain : 1) Perawat yang tinggal serumah dengan suami dan anak dan 2) minimal mempunyai satu anak berusia antara 1-12 tahun yang tinggal bersama.

Pengambilan sampel dalam penelitian ini dilakukan dengan teknk sampling jenuh, yaitu teknik pengambilan sampel dengan mengambil semua populasi untuk menjadi sampel (Sugiyono, 2007). Teknik analisis data yang digunakan untuk melihat ada tidaknya hubungan antara work family conflict dengan psychological well being, penelit menggunakan analisis korelasi Pearson-product moment

\section{HASIL DAN PEMBAHASAN}

\section{Analisis Deskriptif}

Berdasarkan hasil perhitungan batas atas (skor minimum) dan batas atas (skor maksimum), hasil tersebut dimasukan kedalam kategorisasi tiap variabel yang dilihat dalam 4 kategori, yaitu sangat tinggi, tinggi, rendah, dan sangat rendah

\section{Work-Family Conflict}

Berdasarkan hasil analisis dari variabel work family conflictdidapat skor tertinggi adalah 58 dan skor terendah adalah 24

Tabel 1. Kategorisasi Pengukuran

Skala Work-Family Conflict

\begin{tabular}{rlcc}
\hline Interval & Kategori & Frekuensi & $\%$ \\
& & & \\
\hline $48 \square \mathrm{X} \square \square 58$ & $\begin{array}{c}\text { Sangat } \\
\text { Tinggi }\end{array}$ & 7 & 14 \\
& & & \\
\hline $38|\mathrm{X}| \| \mid 48$ & Tinggi & 32 & 64 \\
\hline $28 \square \mathrm{X} \square \square 38$ & Rendah & 9 & 18 \\
\hline $18 \square \mathrm{X} \square \square 28$ & Sangat & 2 & 4 \\
& Rendah & \\
\hline \multicolumn{3}{c}{ JUMLAH } \\
\hline Min = 24 Max $=\mathbf{5 8}$ Mean41,94 SD=10 \\
\hline
\end{tabular}

\section{Psychological Well-Being}

Berdasarkan hasil analisis dari variabel work family conflictdidapat skor tertinggi adalah 93 dan skor terendah adalah 55

Tabel 2 Kategorisasi Pengukuran Skala Psychological Well-Being

\begin{tabular}{cccc}
\hline \multicolumn{1}{c}{ Interval } & Kategori & Frekuensi & $\%$ \\
\hline $5,25 \times 93$ & $\begin{array}{l}\text { Sangat } \\
\text { Tinggi }\end{array}$ & 23 & 46 \\
\hline $9,5 \times 76,25$ & Tinggi & 22 & 44 \\
\hline $2,75 \times 59,5$ & Rendah & 5 & 10 \\
\hline $5 \times 42,75$ & $\begin{array}{l}\text { Sangat } \\
\text { Rendah }\end{array}$ & 0 & 0 \\
\hline \multicolumn{5}{c}{ JUMLAH } \\
\hline Min $=$ 55 Max $=$ 93 Mean 73,96 SD $=\mathbf{1 6 , 7 5}$ \\
\hline
\end{tabular}




\section{Uji Asumsi}

Sebelum melakukan uji korelasi sebagaimana tujuan penelitian ini, peneliti melakukan uji asumsi terlebih dahulu yang terdiri dari uji normalitas dan uji linearitas.

\section{Uji Normalitas}

Uji normalitas yaitu untuk mengetahui apakah data dalam penelitian berdistribusi normal atau tidak. Dikatakan berdistribusi normal jika nilai signifikansi (nilai probabilitas $=$ ) ) lebih dari 0,05 (Santoso, 2002). Berdasarkan hasil pengujian normalitas kedua variabel memiliki signifikansi lebih besar 0,05. Pada variabel work family conflict memiliki nilai KS-Z sebesar 1.073 dengann.signifikansi sebesar 0.199 ( $>00,05)$. Pada variabel psychological well being memiliki nilai $\mathrm{KS}-\mathrm{Z}$ sebesar 0.589 dengan n.signifikansi sebesar 0.878 $(\mathrm{p}>0,05)$.

\section{Uji Linearitas}

Hasil uji linearitas dilakukan untuk mengetahui hubungan antara variabel work family conflict dan variabel psychological well beingdan untuk mengetahui signifikansi penyimpangan dari linearitas hubungan tersebut. Hasil uji linearitas menunjukkan adanya hubungan yang linear antara WFC dengan $P W B$ dengan sebesar $F=30,837, p=0,000$ $(\mathrm{p}>0,05)$.

\section{Uji Korelasi}

Berdasarkan hasil perhitungsn uji korelasi menunjukkan bahwa terdapat hubungan negatif signifikan antara workfamily conflict dengan psychological well-being karena $\mathrm{r}=-0,572$ dan nilai signifikansi $0,000 \quad(\mathrm{p}<0,05)$. Sehingga, hipotesis dalam penelitian ini diterima. Hasil ini menunjukkan bahwa semakin rendah workfamily conflict, maka makin tinggi PWB pada Ibu yang bekerja sebagai perawat di RS Sumber Kasih Cirebon. Demikian sebaliknya, semakin tinggi workfamily conflict, maka semakin rendah PWB pada Ibu yang bekerja sebagai perawat di RS Sumber Kasih Cirebon.

\section{Pembahasan}

Berdasarkan hasil uji korelasi menunjukan adanya korelasi negatif signifikan antara work-family conflict dengan psychological well-being pada Ibu yang bekerja sebagai perawat di RS Sumber Kasih Cirebon dimana $r=-0,572$ dengan nilai signifikansi 0,000 ( $p<0,05)$. Hasil ini menunjukkan bahwa semakin tinggi work-family conflict yang dialami semakain rendah psychological well-being pada Ibu yang bekerja sebagai perawat di RS Sumber Kasih Cirebon demikian pun sebaliknya semakin rendah work-family conflict yang dialami maka semakin tinggi PWB pada Ibu yang bekerja sebagai perawat di RS Sumber Kasih Cirebon. Hal 
ini sejalan dengan penelitian dari Pratiwi (2000) bahwa terdapat hubungan yang negatif antara work-family conflict dengan psychological well-being didukung dengan adanya dukungan sosial dan dedikasi terhadap pekerjaan pada karyawan. Hal ini berarti dengan partisipan menunjukan kemampuan pemikiran yang berbeda dan menurut Putrianti (2007) berpendapat bahwa perempuan yang bekerja cenderung mempunyai pola pikir yang lebih terbuka, lebih energik, mempunyai wawasan yang luas dan lebih dinamis.

Sebagai seorang perawat para wanita harus membagi waktu dan perannya dalam satu waktu. Seorantg perawat wanita yang mengalami work family conflict dikarenakan tidak bisa menyeimbangkan satu peran (sebagai ibu) terhadap peran lainnya (sebagai perawat. Dimana Urusan pribadi sebagai ibu dan bekerja akan sejalan setiap harinya dan tidak akan menjadi hal yang tidak bisa simbang dan menciptakanwork family conflict (Prawitasari, 2007).Proses pencapaian psychological well-being pada ibu bekerja. Dari hasil wawancara dengan ketiga ibu yang yang menjadi perawat dan mengalami work family conflictadalah menggunakan jasa asisten rumah tangga.

Ciri individu memiliki work family conflict yang rendah dan PWB yang tinggi adalah mengakui pekerjaan dan tanggung jawab sebagai ibu merupakan bagian dari hidup, terkait dengan kepentingan dan pemenuhan dari dalam diri. Hal ini berarti, ketegangan yang disebabkan oleh pertentangan antara peran dirumah dan di tempat kerja memengaruhi PWB dalam diri individu( Ajeng, 2016) oleh karena itu terdapat hal positif dan negatif yang harus diseimbangkan

\section{PENUTUP}

\section{Kesimpulan}

Berdasarkan hasil penelitian maka didapatkan kesimpulan, Ada hubungan negatif signifikan work family conflict dengan psychological well being pada Ibu yang bekerja sebagai perawat di RS Sumber Kasih Cirebon. Sebagian besar subjek dalam penelitian $64 \%$ memiliki work family conflict pada kategori tinggi, dan sebagian besar subjek $46 \%$ memiliki psychological well being pada kategori sangat tinggi. Sumbangan yang diberikan work family conflict terhadap psychological well being sebesar 32,71\% dan sisanya $67,29 \%$ dipengaruhi oleh faktor lain.

\section{Saran}

Berdasarkan hasil penelitian, maka terdapat beberapa saran yang dapat diberikan penulis:

Bagi subjek. Perlunya komunikasi yang baik agar pembagian kerja yang seimbang 
antara suami, istri dan anak, lalu bukan hanya keluarga akan tetapi lingkungan kerja dan jika semua pihak mendukung maka akan terpenuhi tugas rumah tangga. Bagi peneliti selanjutnya. Dapat digunakan sebagai tambahan refrensi

DAFTAR PUSTAKA

Ajeng, Syntia SA, I.G.A. 2016. Hubungan Antara Konflik Peran Ganda Dengan Psychological Well Being Pada Ibu Yang Bekerja Sebagai Kowad. (skripsi). Salatiga: Fakultas Psikologi Universitas Kristen Satya Wacana

Amaliya, Riza. 2015. A Literature Review Work Family Conflict And Subjective Well Being Inworking Woman Factors Related To Both Variable. Seminar Psikologi \& Kemanusiaan. Malang: Magister Psikologi Universitas Muhammadiyah Malang. ISBN: 978979-796-324-8

Amawidyati, Sukma A.G \& Muhana S.U. 2007. Religiusitas dan psychological well-being Pada Korban Gempa. Jurnal Psikologi. Universitas Gajah Mada Yogyakarta. Vol. 34, No.2, 164-176.

Badan Pusat Statistik. 2018. Presentase Tenaga Kerja Formal Menurut Jenis Kelamin 2015-2017. Diakses July 30, 2018. Available from : http://www.bps.go.id/linkTabelStatis/v iew/id/1606

Compton, Wiliam C. 2005. Introduction to Positive USA:Wadsworth Psychology.

Greenhaus, J.H. \& Beutell, N.J. 1985. Sources of conflict between work and family roles. Academy of Management Review, 10, 76-88 untuk penelitian selanjutnya dan bisa juga melanjutkan penelitian ini dengan subjek yang sama dikaitkan atau ditambahkan dengan variabel lain agar dapat memberikan refrensi yang banyak.

Gruyter, Aldine de. 2003. John Morowsky and Catherine E. Ross: Education, Social Status and Health. Canadian Jurnal of Sociology Online, 242pp

Handayani, Dias Tri dkk. 2011. Perbedaan Psychological Well-Being Ditinjau Dari Strategi Self -Management Dalam Mengatasi Work-Family Conflict Pada Ibu Bekerja. Jurnal Psikologi: Program Studi Psikologi Fakultas Kedokteran Universitas Sebelas Maret Surakarta. Vol. 3, No.2

Herbyanti, Deni. 2009. Kebahagiaan (Happiness) Pada Remaja Daerah Abrasi. Jurnal Ilmiah Bekala Psikologi Fakultas Psikologi Universitas Muhammadiah Surakarta. Vol. 11, No.2

Indriani, Defi \& Inhastuti Sugiasih. 2016. Dukungan Sosial Dan Konflik Peran Ganda Terhadap Kesejahteraan Psikologis Karyawati PT.Sc Enterprices Semarang. Jurnal Psikologi: Fakutas Psikologi Universitas Islam Sultan Agung Semarang. Vol.11, No.1 2016,46 - 54

Munandar, Haris, dkk. 2018. Subjective well-Being Pada Pekerja Perempuan. Magister Psikologi Sains Universitas Ahmad Dahlan.

Netermeyer, R.G., Boles, J.S, McMurrian, R (1996). Development And Validation Of Work-Family Conflict And Family-Work Conflict Scales. 
Journal of Applied Psychology, 81, 400-410

Pratiwi, D., \& Pratiwi, A. (2000). Hubungan konflik peran ganda dengan psychological well being pada ibu bekerja sebagai pegawai bank. Jurnal Psikologi. Vol. 1, No.3, 20-35

Putrianti, F. G. (2007). Kesuksesan Peran Ganda Wanita Karir Ditinjau Dari Dukungan Suami, Optimisme, Dan Strategi Coping. Jurnal Ilmiah Berkala Psikologi. Vol. 9, No. 1,3-17

Raprap, Aleangger R.H. 2016. Hubungan Religiusitas Dengan Psychological Well-Being Pada Anak Pendeta Sebagai Mahasiswa Di Universitas Kristen Satya Wacana. (Skripsi). Salatiga: Fakultas Psikologi Universitas Kristen Satya Wacana.

Rosyad, Alfi Sabella. 2017. Hubungan Konflik Peran Ganda (Work Family Conflict) Terhadap Stres Kerja Perawat Wanita Di Ruang Rawat Inap, Intensive Care Dan IGD RSUD Tugurejo Semarang. (Skripsi). Semarang: Fakultas Psikologi Universitas Diponogoro.

Ryff, C. D. 1995. Psychological WellBeing in Adult Life. Journal Current Direction In Psychological Science. Vol. 4, No.4, pp. 99-104
Ryff, C. D. 1989. Happiness is everything, or is it? Explorations on the meaning of psychological well-being. Journal of Personality and Social Psychology. Vol.57, No.6, 1069-1081

Sahusilawane, Lourista, Yulius Yusak R \& Desi. 2017. Hubungan antara psychological well-being perawat dengan psychological well-being pasien anak. Jurnal keperawatan Muhammadiyah. Universitas Kristen Satya Wacana. Vol.2, No.2

Saman, Abdul \& Eva Meizara Puspita Dewi. 2012. Pengaruh Motivasi Kerja Dan Dukungan Suami Terhadap Stres Konflik Peran Ganda Dan Kepuasan Perkawinan Pada Wanita Karir. Jurnal Psikologi: $\quad$ Teori\&Terapan. Universitas Negeri Makasar. Vol.2, No. 2

Sugiyono. (2007). Metode Penelitian Kuantitatif Kualitatif Dan $R \& D$. Bandung: Alfabeta

Sianturi, Maria Mayasari dan Zulkarnain. (2013). Analisis Work Family Conflict Terhadap Kesejahteraan Psikologi Pekerja. Jurnal Sains dan Praktik Psikologi. Medan : Universitas Sumatera Utara. Vol.1, No.3 